\title{
Efficacy of Different Doses of Oral Midazolam for Pre Operation Sedation of Children
}

\author{
Faranak Beirami, ${ }^{1}$ Masoum Khoshfetrat, ${ }^{1, *}$ Saeede Babaiyan, ${ }^{1}$ and Alireza Ansari-Moghadam ${ }^{2}$ \\ ${ }^{1}$ Departement of Anesthesiology, Ali ibne Abitaleb Hospital and Research Center, Medical Faculty, Zahedan University of Medical Sciences, Zahedan, IR Iran \\ ${ }^{2}$ Health Promotion Research Center, Zahedan University of Medical Sciences, Zahedan, IR Iran \\ "Corresponding author: Masoum Khoshfetrat, Departement of Anesthesiology, Ali ibne Abitaleb Hospital and Research Center, Medical Faculty, Zahedan University of Medical \\ Sciences, Zahedan, IR Iran. E-mail: drkhoshfetrat@yahoo.com
}

Received 2015 April 23; Accepted 2015 October 12.

\begin{abstract}
Background: One of the major problems in pediatric surgery is anxiety and fear of separation from parents. Objectives: We studied the efficacy of different doses of oral midazolam for pre operation sedation of children.

Patients and Methods: In this randomized, double-blinded clinical trial, 120 children aged 1 - 8 years were enrolled in the study .The children were randomly assigned to one of 4 groups and received orally $0.5 \mathrm{mg} / \mathrm{kg}$ (group A), $0.8 \mathrm{mg} / \mathrm{kg}$ (group B), $1 \mathrm{mg} / \mathrm{kg}$ (group C), $0 \mathrm{mg} / \mathrm{kg}$ (group D) of injectable midazolam mixed with 10 - $15 \mathrm{~mL}$ apple juice 45 minutes before separation from parents. Sedation score, changes in MAP, HR, SPO2, respiratory rate, time of recovery and frequency of nightmares evaluated and analyzed with Kruskal-Wallis and ANOVA tests.

Results: The mean age of children was $4.46 \pm 2.17$ years. Sedation levels in 26 patients in group A and 21 patients in group C were desirable qualified. MAP changes increased in group $\mathrm{D}$ and decreased in the other groups. Most changes were observed in group $\mathrm{C}$ equals $-3 \pm 2.5 \mathrm{mmHg}$. Most changes in heart rate were observed in group D (increased to $11.5 \pm 7.41$ beat). Most decrease of SPO2 was in group A (-0.86 $\pm 0.93 \%)$. Maximum decrease of RR was in group C (-3.36 $\pm 2.88 \%)$. Maximum of recovery time was observed in group C (76.3 \pm 12.67 minutes). Group D had the highest frequency of nightmares (10 children, $58.8 \%)$.

Conclusions: Oral midazolam with $0.8 \mathrm{mg} / \mathrm{kg}$, as premedication, reduces recovery time and hemodynamic disturbances .We can use that as appropriate premedication dose in children for reducing children anxiety and fear of separation from parents.

Keywords: Midazolam, Children, Sedation
\end{abstract}

\section{Background}

One of the major concerns in children's surgery is their fear of surgery and parents' separation anxiety, which may cause permanent psychological effects on them. Pharmacologic and psychological preparation for operation is called Premedication [1]. Anxiety is a psychological condition that may appear in many cases. In children whom are surgery candidate and in the time of separation from parents it may appear as irritability, insomnia, and bizarre behavior [2].

Pharmacologic and psychologic preparation were shown to have synergistic effects [1]. Premedication is particularly essential in children older than 10 -12 months old, in whom parents separation anxiety begins to develop [3]. Premedication agents are administered in oral, intravenous, intramuscular, rectal, or nasal root. Oral root is preferred. The most common drugs which are used are Benzodiazepines. In addition to their sedative effects, they have other desirable features: acquiring new knowledge without obvious changes in background, the lowest cardiopulmonary depression, and relative safety in overdose, rare addiction, and having selective antagonist -Flumazenil- to neutralize their central nervous system CNS effects [4]. Factors that may influence the pharmacokinetics of benzodiazepines are age, gender, race, enzyme induction, and hepatic and renal disease [5].

Among these drugs, midazolam is more used as premedication agent. It is only benzodiazepine approved by FDA (food and drug administration) for neonates. It's sedative and anti-anxiety effects were induced by several doses and success rate was about $50 \%-80 \%$ [5]. Midazolam is a water soluble, chemically midazolam HCL IS 8-CHLORO6(2-Fluorophenyl)-1-methyl-4H- imidazole $(1,5 \mathrm{a})$ benzodiazepine hydrochloride [6]. Midazolam is frequently administered through oral and rectal routes, but bioavailability is only $40 \%$ for oral the oral route [7]. The intramuscular route is painful and has poor acceptability [8]. The intranasal route has been in practice since 1988.through the latter, midazolam is rapidly absorbed directly into systemic circulation, with a bioavailability of $55 \%-83 \%$ [9, 10] but it can be irritating [3] and oral route versus nasal route have better acceptance in children [11]. Oral mi- 
dazolam is the most commonly administered premedication in the United States [3]. After oral ingestion midazolam is absorbed completely, and the peak plasma concentration is achieved in $30-80$ minutes. It exert own action through GABAA receptors which are the key targets that mediate most of the clinically important effects [5]. The elimination half-life ranges from 1.7 to 3.5 hours. Midazolam is metabolized by CYP3A4 and CYP3A5 to its main metabolite 1-hydroxymidazolam and minor metabolite 4-hydroxymidazolam and 1, 4-hydroxymidazolam the metabolites are cleared more rapidly than midazolam, thus making them of little concern in patients with normal hepatic and renal function. In patients with renal impairment, however, the main metabolite and its conjugated metabolite can cause profound sedation [3].

\section{Objectives}

In this study, we want to find the best dose of oral midazolam with minimum recovery time and hemodynamic complications. It can be different from other studies because of different races.

\section{Patients and Methods}

After approval from the university ethics committee and obtaining written informed consent from parents of children, one hundred and twenty (120) children of ages 1 - 8 years, referred to Aliibn AbiTalib and Khatamolanbiya hospitals in Zahedan, were randomized in four groups, receiving Midazolam (Daropakhsh company Tehran-Iran) $0.5 \mathrm{mg} / \mathrm{kg}$ (group A), $0.8 \mathrm{mg} / \mathrm{kg}$ (group B), $1 \mathrm{mg} / \mathrm{kg}$ (group C) or $0.0 \mathrm{mg} / \mathrm{kg}$ (group D).

1 to 8 years old patients with ASA (American society of Anesthesiologists) physical class status of I-II admitted for elective herniorrhaphy were selected and those with: 1, renal disease; 2 , liver disease; 3 , active central nervous system (CNS) disease; 4, history of receiving Erythromycin; 5, history of receiving calcium channel blockers; 6 , history of receiving anti convulsive drugs; 7 , grapefruit usage were excluded.

Children of 1 to 3 years old for 6 hours and older children for 8 hours prior to surgery received no food and they had no oral fluid intake up to $4 \mathrm{~h}$ before surgery.

Patients were fed 45 minutes before separation from their parents by drug or placebo solved in $10-15 \mathrm{cc}$ of apple juice. Patients and their parents were blinded to the used dose. Peripheral oxygen saturation (Spo2), pulse rate (PR), respiratory rate (RR), and mean arterial pressure (MAP) (Monitor: Siemens sc 7000) were registered by a blinded colleague, after drug intake and before entrance to operation room.
Several rating scales have been developed to communicate a patient's level of sedation more easily. One of the most common scales, Ramsay scale simply rates the patients level of arousal from anxiety or agitation (level 1) to deep sedation (level 4,5) to anesthetized (level 6) [12-14].

In our study, patient's consciousness was assessed with modified Ramsay scales (Table 1).

Anesthesia was induced by Fentanyl $0.5-1 \mathrm{mg} / \mathrm{kg}$ and Nesdonal $5 \mathrm{mg} / \mathrm{kg}$. Patients underwent mechanical ventilation with appropriate LMA. During operation (one surgeon done all surgeries) anesthesia was maintained by 50 percent mixture of Nitrous oxide/Oxygen and Propofol 6 - $12 \mathrm{mg} / \mathrm{kg} /$ hour to maintain cerebral state index at 40 60. In Recovery room, after removal of LMA, until patients gain full score of Table 2 (Deliberate movements of limbs, deep breath, and full consciousness), time was measured in minutes and recorded as recovery time. In next 24 hours, parents were asked about nightmares. Finally, data were analyzed, by ANOVA and Kruskal-Wallis through SPSS version. 19. Statistic of significance was determined at $\mathrm{P}<$ 0.005 .

\section{Results}

Mean age of population study was $4.46 \pm 2.17$ with min of 1 and max of 8 years old. 61 patients (50.8\%) were male and 59 patients (49.2\%) were female. There was no significant difference between patients in their age and gender $(\mathrm{P}>0.05)$.

Most of patients (86.7\%) in group B have an appropriate sedation level after the surgery. In group C two third (70\%), in group $\mathrm{A}$ just one third (33.3\%) and in group $\mathrm{D}$ few patients (13.2\%) had the same condition (Ramsay 2 and 3). However, in rest one third of children in group C, sedation level was excessive (Ramsay $>3$ ) and higher than our need (Table 1).

MAP (mean arterial pressure) was decreased in all groups except group D (control). Max of MAP changes was seen in group $\mathrm{C}(-3 \pm 2.9 \mathrm{mmHg})$ and Min MAP changes was in group $\mathrm{A}(-6 \pm 3.7 \mathrm{mmHg})$. It was significant before and after treatment in all groups except in group B. Changes in group $\mathrm{C}$ was the most which was inappropriate. Heart rates in observed groups show different changes. Max of these changes which was unfavorable was seen in group D, with $11.5 \pm 7.41$ increased beat. On the other hand, min of changes was in group $C$ with $1.13 \pm 6.04$ decreased beats. Heart rates changes after treatment was significant in all groups except group A, Mean of these changes between all groups was significant $(\mathrm{P}<0.001)$ (Table 2 ).

$\mathrm{SPO} 2$ was decreased in all groups. Max of this decrement was in group A with - $0.86 \pm 0.93$ and min was in group D with $0.06 \pm 1.48$. SPO2 changes were significant 
Table 1. Comparison of Sedative Level Between Groups (Modified Ramsay Scale) ${ }^{\mathrm{a}}$

\begin{tabular}{|c|c|c|c|c|c|}
\hline Sedative Level & Group A & Group B & Group C & Group D & Total \\
\hline Anxious, agitated, rest-less (1) & $20(66.7)$ & $4(13.3)$ & $0(0)$ & $26(86.7)$ & $50(41.7)$ \\
\hline Cooperative,oriented, tranquil, responsive to commands $(2,3)$ & $10(33.3)$ & $26(86.7)$ & $21(70)$ & $4(13.3)$ & $61(50.8)$ \\
\hline Asleep $(4,5,6)$ & $0(0)$ & $9(30)$ & $9(30)$ & $0(0)$ & $9(5.7)$ \\
\hline Total & $30(100)$ & $30(100)$ & $30(100)$ & $30(100)$ & $120(100)$ \\
\hline
\end{tabular}

${ }^{\mathrm{a}}$ Values are expressed as No. (\%).

Table 2. Variables' Changes in Observed Groups ${ }^{\mathrm{a}}$

\begin{tabular}{|c|c|c|c|c|c|}
\hline Variables & $0.5 \mathrm{mg} / \mathrm{kg}(\mathrm{A})$ & $0.8 \mathrm{mg} / \mathrm{kg}(B)$ & $1 \mathrm{mg} / \mathrm{kg}(\mathrm{C})$ & $\operatorname{Placebo}(\mathrm{D})$ & P Value \\
\hline MAP changes, $\mathrm{mmHg}$ & $-0.6 \pm 3.7$ & $-2.9 \pm 2.5$ & $-3.2 \pm 2.9$ & $1.9 \pm 4.0$ & $<0.001$ \\
\hline HR change, beats/minute & $2.2 \pm 7.3$ & $-1.1 \pm 7.6$ & $-1.2 \pm 6.0$ & $11.5 \pm 4.7$ & $<0.001$ \\
\hline $\mathrm{SPO}_{2}$ changes, percent & $-0.8 \pm 0.9$ & $-0.8 \pm 1.2$ & $-0.7 \pm 1.7$ & $0.0 \pm 1.4$ & $<0.009$ \\
\hline Respiratory changes, numbers/minute & $-0.5 \pm 3.7$ & $-1.7 \pm 3.9$ & $-3.4 \pm 2.8$ & $3.6 \pm 3.1$ & $<0.001$ \\
\hline Recovery time, minutes & $43.4 \pm 10.5$ & $52.7 \pm 9.1$ & $76.3 \pm 12.6$ & $35.0 \pm 6.8$ & $<0.001$ \\
\hline Having nightmares (Person), No. (\%) & $5(29.4 \%)$ & $1(5.8 \%)$ & $1(5.8 \%)$ & $10(58 \%)$ & $<0.002$ \\
\hline
\end{tabular}

Abbreviations: HR, heart Rate; MAP, mean arterial pressure; $\mathrm{Spo}_{2}$, peripheral $\mathrm{O}_{2}$ Saturation.

${ }^{\mathrm{a}}$ Values are expressed as mean $\pm \mathrm{SD}$ unless otherwise indicated.

just in group $\mathrm{A}$ and $\mathrm{B}(\mathrm{P}<0.001$ and $\mathrm{P}=0.002)$ Mean of these changes was not significant in groups $(P=0.09)$.

Respiratory Rate was increased just in group $\mathrm{D}$ and in the other groups in was increased. Max of this unfavorable decrement was in group $C$ with $-3.36 \pm 2.88$ and group A has the min of changes with $-0.46 \pm 3.74$. Respiratory rate changes before and after treatment was significant in all groups except group A $(\mathrm{P}=0.12)$ Mean of these changes between all groups was significant $(\mathrm{P}<0.001)$ (Table 2$)$.

Mean of surgery plus recovery Time in all observed children was a $51.88 \pm 18.39$ minute which was significant between groups $(\mathrm{P}<0.001)$. Max of these times was in group $\mathrm{C} 76.3 \pm 12.67$ and shows a delay in patient's recovery. Min of these times was in group D with $35.3 \pm 6.82$. Most of children did not have nightmares (103 children, $85.8 \%$ ). In group D more than half of patients and in group B one third of patients have nightmares. It was significant between groups $(\mathrm{P}=0.002)$ (Table 2$)$.

\section{Discussion}

According to results, Children in group $\mathrm{B}$ and $\mathrm{C}$ have a better sedative level. After treatment MAP was decreased in all groups except placebo, max of this unfavorable decrement was in group C. After treatment SPO2 was also decreased in all groups with a max in group A and min Placebo group. Except placebo group Respiratory Rate was also decreased in all groups, this unfavorable decrement was most seen in group C. The max of recovery time was in group $\mathrm{C}$ and the min was in placebo group which was half of the max. The most nightmares were reported in placebo group and then group $\mathrm{A}$.

The findings of the current study was consistent with those of Spear et al. in 1991, in which there were no significant change in blood pressure, Hear rate, SPO2, end expiratory $\mathrm{CO} 2$ in first 10 minutes in patients treated with oral Midazolam $0.5 \mathrm{mg} / \mathrm{kg}$. In this study sedation was obvious in higher dose (1 mg/kg) and there was a delay in recovery time up to 60 minutes in higher dose ( $2 \mathrm{mg} / \mathrm{kg}$ ), in agreement with our study [15]

Due to Cote et al. study in 2002, there was correlation between different doses of midazolam (0.25 - $0.5 \mathrm{mg} / \mathrm{kg}$ ) and onset of sedation, but it has no correlation with recovery time. In this study respiratory complication (hypoventilation, apnea, and decrease in SPO2) was seen in all groups but it was at least until $0.25 \mathrm{mg} / \mathrm{kg}$. However, in our study different doses of midazolam was correlated with recovery time and respiratory complications were rare probably because of different races [16].

Our findings are in agreement with Chernow et al. study in which midazolam was given $0.75-1 \mathrm{mg} / \mathrm{kg}$ and their recovery time was about 60 minutes [17].

Gautam et al. in 2007, the effects of midazolam on 1 - 7 years old children were observed. Most parents were sat- 
isfied about sedation, resistance and crying of their children. Parent's separation also was better tolerated in patients treated with nasal Midazolam $0.2 \mathrm{mg} / \mathrm{kg}$ in compression with Ketamine [18].

There was a significant difference between sedative effects of midazolam and placebo in Stokland et al. study in 2007. In this study, $96 \%$ of patient in Midazolam group in compression with $70 \%$ of placebo group were sedated that was in agreement of our study [19].

In 2002, Kogan et al. published a paper in which, they showed that midazolam has effective features in sedating and decreasing anxiety before induction of anesthesia. When it was used through nasal root its effects appear in 20 minutes and it made IV catheterization and mask holding easier in more than $75 \%$ of children in ages of 1 to 5 years old [20].

In another study done by Vivarelli et al. in 1998, 0.2 $\mathrm{mg} / \mathrm{kg}$ nasal midazolam made IV catheterization and mask holding easier and provided a better preparation before induction [21].

Sajedi et al. compared $0.5 \mathrm{mg} / \mathrm{kg}$ oral midazolam and $0.2 \mathrm{mg} / \mathrm{kg}$ nasal midazolam on 60 healthy 1 to 5 years old children. Anxiety while administration was significantly lower in oral root. In other aspects (heart rate and postsurgery nausea and vomiting) no significant difference was seen [22].

In Kaviani study on 60 children in 3 to 7 years old, effects of $0.5 \mathrm{mg} / \mathrm{kg}$ oral midazolam was compared with $6 \mathrm{mg}$ Ketamin while dentistry procedures. In midazolam group, consciousness, movement, crying and general behavior was better according to Houpt scale. They also have a shorter recovery time [23].

In 2007, Hasani et al. published a paper in which 2 - 6 years old children received either $0.5 \mathrm{mg} / \mathrm{kg}$ rectal Diazepam (48 patients) or $0.5 \mathrm{mg} / \mathrm{kg}$ oral midazolam (49 patients). Sedation before induction due to Ramsay scales, was better in rectal Diazepam insignificantly [24].

In Naziri et al. study on 56 children in class 1 ASA, Separation from parents was easier in patients treated with 0.3 $\mathrm{mg} / \mathrm{kg}$ oral midazolam than whom treated with $1 \mathrm{mg} / \mathrm{kg}$ oral promethazin $(\mathrm{P}=0.019)$. Recovery time was appropriate in $78.6 \%$ patients in midazolam group and $53.6 \%$ patients in promethazin group [25].

In conclusion, According to the results of this study, we demonstrated that the oral midazolam $0.8 \mathrm{mg} / \mathrm{kg}$ can be used as the suitable dose for premedication in children to reduce anxiety and fear of separation from parents with little complications and intermediate recovery time. For further studies with different doses are required to find the best dose of midazolam as Pre-medication; it may be evaluated in more patients and more surgeries.

\section{Acknowledgments}

We would like to thank all the operating room personnel of Ali ibn Abitaleb hospital. Thesis No:T/508 and director was M. Khoshfetrat.

\section{Footnotes}

Authors' Contribution: Faranak Beirami, giving anesthesia according the proposal for most cases of study and translating the paper in English; Masoum Khoshferat: giving anesthesia according the proposal in some cases of study and writing the paper in persisn; Saeede Babaiyan, writing proposal and filling forms of study for each case of study; Alireza Ansari-Moghadam, statistical analysis.

Conflict of Interest: No conflict of interests.

Funding/Support: Zahedan university of Medical sciences

\section{References}

1. Nyhus L, Baker R, Fischer J. The Mastery of surgery. 3rd ed. ; 1997. pp. 39-44.

2. Kain ZN, Mayes LC, O'Connor TZ, Cicchetti DV. Preoperative anxiety in children. Predictors and outcomes. Arch Pediatr Adolesc Med. 1996;150(12):1238-45. [PubMed: 8953995].

3. Miller RD, Eriksson L, Fleisher LA. Pediatric Anesthesia. 8th ed. ; 2015.

4. Meredith JR, O'Keefe KP, Galwankar S. Pediatric procedural sedation and analgesia. J Emerg Trauma Shock. 2008;1(2):88-96. doi: 10.4103/0974-2700.43189. [PubMed: 19561987].

5. Miller RD, Eriksson L, Fleisher LA. Intravenous Anesthesia. 8th ed. ; 2015.

6. Malamed SF. Sedation: a guide to patient management. Elsevier Health Sciences; 2009.

7. Riss J, Cloyd J, Gates J, Collins S. Benzodiazepines in epilepsy: pharmacology and pharmacokinetics. Acta Neurol Scand. 2008;118(2):69-86. doi: 10.1111/j.1600-0404.2008.01004.x. [PubMed:18384456].

8. Karl HW, Rosenberger JL, Larach MG, Ruffle JM. Transmucosal administration of midazolam for premedication of pediatric patients. Comparison of the nasal and sublingual routes. Anesthesiology. 1993;78(5):885-91. [PubMed: 8489062].

9. Gudmundsdottir H, Sigurjonsdottir JF, Masson M, Fjalldal O, Stefansson E, Loftsson T. Intranasal administration of midazolam in a cyclodextrin based formulation: bioavailability and clinical evaluation in humans. Pharmazie. 2001;56(12):963-6. [PubMed: 11802661].

10. Knoester PD, Jonker DM, Van Der Hoeven RT, Vermeij TA, Edelbroek PM, Brekelmans GJ, et al. Pharmacokinetics and pharmacodynamics of midazolam administered as a concentrated intranasal spray. A study in healthy volunteers. Br J Clin Pharmacol. 2002;53(5):501-7. [PubMed: 11994056].

11. Verma RK, Paswan A, De A, Gupta S. Premedication with midazolam nasal spray: an alternative to oral midazolam in children. Anesth Pain Med. 2012;1(4):248-51. doi: 10.5812/aapm.4567. [PubMed: 24904809].

12. Vincent JL, Abraham E, Moore FA. Agitation and delirum. 6th ed.;2011.

13. Begum MF, Rahman MA, Alam MF. Biological Control of Alternaria Fruit Rot of Chili by Trichoderma Species under Field Conditions. Mycobiology. 2010;38(2):113-7. doi: 10.4489/MYCO.2010.38.2.113. [PubMed: 23956637]. 
14. Sheta SA, Alsarheed M. Oral midazolam premedication for children undergoing general anaesthesia for dental care. Int J Pediatr. 2009;2009:274380. doi: 10.1155/2009/274380. [PubMed: 19946418].

15. Spear RM, Yaster M, Berkowitz ID, Maxwell LG, Bender KS, Naclerio R, et al. Preinduction of anesthesia in children with rectally administered midazolam. Anesthesiology. 1991;74(4):670-4. [PubMed: 2008948].

16. Cote CJ, Cohen IT, Suresh S, Rabb M, Rose JB, Weldon BC, et al. A com parison of three doses of a commercially prepared oral midazolam syrup in children. Anesth Analg. 2002;94(1):37-43. [PubMed: 11772797] table of contents.

17. Chernow B, Alexander HR, Smallridge RC, Thompson WR, Cook D Beardsley D, et al. Hormonal responses to graded surgical stress. Arch Intern Med. 1987;147(7):1273-8. [PubMed:3606284]

18. Gautam SN, Bhatta S, Sangraula D, Shrestha BC, Rawal SB. Intranasal midazolam Vs ketamine as premedication in paediatric surgical procedure for child separation and induction. Nepal Med Coll J 2007;9(3):179-81. [PubMed:18092436].

19. Stokland E, Andreasson S, Jacobsson B, Jodal U, Ljung B. Sedation with midazolam for voiding cystourethrography in children: a randomised double-blind study. Pediatr Radiol. 2003;33(4):247-9. doi 10.1007/s00247-003-0874-0. [PubMed: 12709753].
20. Kogan A, Katz J, Efrat R, Eidelman LA. Premedication with midazolam in young children: a comparison of four routes of administration. Paediatr Anaesth. 2002;12(8):685-9. [PubMed: 12472704]

21. Vivarelli R, Zanotti F, Battaglia D, Caggese G, Stella G, Gilli G, et al. [Premedication with intranasal midazolam in children of various ages]. Minerva Anestesiol. 1998;64(11):499-504. [PubMed: 9951268].

22. Sajedi P, Attari MA, Ghorbani A. Comparing effectiveness of oral and intranasal midazolam for premeditation in children. J Res Med Sci. 2000;5(1).

23. Kaviani N, Eshghi AR, Tabibian P. Comparative evaluation of sedative effects of oral midazolam and oral ketamine in combination with inhalation sedation for pediatric behavior control during dental treatment. 2007

24. Hasani VA, Fathi M, Saadatniaki AA. Evaluation of anti anxiety effect of rectal diazepam as a premedication with oral midazolam on children who are undergoing eye surgery. 2009

25. Naziri F, Alijanpour E, Rabiei SM, Seyfi SH, Mir M, Hosseinpour M, et al. Comparison of oral Midazolam with oral Promethazine on decreasing anxiety of children when separated from their parents before anesthesia. 2007 